\title{
Predictors of Psychosomatic Health during the first COVID-19 Outbreak in Greece. A Multiple Linear Regression Analysis in an Epidemiological Sample of 1,156 Individuals
}

\author{
Georgios Pilafas ${ }^{1}$, Alexandra Prouzou ${ }^{1}$, Nefeli Paraskevi Strongylaki ${ }^{2}$, \\ Despina Menti ${ }^{3}$, Georgios Lyrakos ${ }^{4}$
}

${ }^{1}$ MSc, Research Associate, CityU Research Center, Psychology Laboratory, City Unity College, Athens, Greece

${ }^{2} \mathrm{MSc}, \mathrm{MBPsS}$, Research Associate, CityU Research Center, Psychology Laboratory, City Unity College, Athens, Greece

${ }^{3}$ PgDip, MSc, PhD, CPsychol, EuroPsy, Psychology Lecturer, Department of Psychology, Cardiff Metropolitan University at City Unity College, Athens, Greece

${ }^{4} \mathrm{MSc}, \mathrm{MPH}, \mathrm{PhD}$, PostDoc, 'MSc Health Psychology' Program Director, Department of Psychology, Cardiff Metropolitan University at City Unity College, Athens, Greece; and 'Clinical Health Psychologist', Psychiatric Department, General Hospital of Nikaia 'Ayios Panteleimon', Athens, Greece

Corresponding Author: Georgios Pilafas

\begin{abstract}
Background: Between March 23 and May 4, 2020, the Greek government established an economic and social 'lockdown' to prevent the spread of COVID-19. It was hypothesized that the unsafe environment activated the stress response of the Greeks during that time, while existing literature supports the development of psychosomatic disorders.

Aim: The research question is whether six biopsychosocial variables predict psychosomatic symptoms of the Greek general population during the 'lockdown'.

Methods \& Materials: A convenient sample of 1,158 -of whom 2 were excluded from the final analysis- Greeks participated electronically during the 'lockdown'. Pearson's $r$ and a linear-multiple regression analyses were chosen to test the hypothesis. The participants answered a series of demographic questions, while the rest variables were measured through the following self-reported psychometric tools: 'psychosomatics' [PSSQ-29], 'acute stress' [ASDS], 'psychological resilience' [NMRQ], and 'satisfaction with life' [SWLS].

Results: Between the significant predictors, the first to appear is 'acute stress' $(\beta=.66, \mathrm{p}<.001)$, while 'psychological resilience' $(\beta=.21, \mathrm{p}<.001)$, 'satisfaction with life' $(\beta=.06, \mathrm{p}=.001)$ and 'age' $(\beta=.04, \mathrm{p}=.025)$ follow hierarchically.

Discussion: The findings are consistent to the background literature and previous relevant COVID-19 studies, with the exception of the findings regarding 'gender' -which was not found significant in the weightings-.

Conclusion: The model predicts the criterion with a large effect. The study is overall confirmatory to previous COVID-19 research regarding domestic general population, while the need for European studies that would include positive components on psychosomatic health is highlighted.
\end{abstract}

Keywords: Psychosomatic Health; COVID-19; Greece; Acute Stress Disorder; Psychological Resilience

\section{INTRODUCTION}

The 'Coronavirus Disease 2019' (COVID-19) was first introduced to the
Greek people by the local media of massive communication as a pneumonia outbreak in Wuhan, China. There was a rapid increase 
in the numbers of infections, and within a very brief period of time over 100,000 cases were confirmed globally. ${ }^{[1]}$ On the $30^{\text {th }}$ of January of 2020, the World Health Organization (WHO) declared that COVID19 is an 'international public health emergency', while on the $11^{\text {th }}$ of March of 2020 COVID-19 was eventually declared a 'global pandemic' by the same organization [1] In Greece, 'patient zero' was diagnosed on February 26, 2020. From that day, the Greek government started to establish measures against the spread of the disease in the country. The first measures included the cancellation of all carnival events, the closure of schools and the suspension of cultural events in regions where COVID-19 had infected someone from the local community. ${ }^{[2]}$ The fast increase in the number of infections throughout the state, as well as the statistics that were observed from China, Italy and the rest of the Western European countries regarding the rapid spread and deaths, led the Greek government to establish further obligatory precaution measures.

The final measures were enforced by state authorities, including the police, from March $23^{\text {rd }}$ to May $4^{\text {th }}$ of 2020. The measures were the same in all regions of Greece and included the prohibition of any in person social interaction, while any physical business and economic transaction was forbidden. Schools, universities and most of private and public businesses and organizations were closed. Employees and employers were allowed to work only from their houses, if the company or the organization could support that, while all citizens were enforced to stay at home. If any person was diagnosed positive to COVID-19, s/he was obligated to be in a 14-day quarantine without any physical contact with any other person. ${ }^{[1]}$ All physical contacts were not allowed between members of different households, and a distance of 2 meters between individuals was imposed. Free movement was also prohibited, with the exceptions of moving to or from the workplace, visiting a medical doctor, providing help to an ill or disabled member of the family, walking outdoors with the household pets or perform physical exercise for less than one hour in a close proximity to the address of the permanent residence and lastly, buying basic goods from the local supply store. ${ }^{[3]}$ Greek citizens who did not obey and follow these compulsory measures were fined by the police, while in a very limited number of cases people who were infected and did not follow the 14-day quarantine were arrested by the police and were accused of criminal charges for exposing other citizens into danger and the disease.

Regarding the psychological impact of the COVID-19 pandemic in the life of Greek citizens, the local mass media presented to the public the ratio of infections and deaths from other countries. Many related scientists were hosted to the news and their opinions were referenced by many reporters. These opinions were narrowed to the point that COVID-19 is a deadly disease without any medical cure, and which can be spread very rapidly. Moreover, many economists highlighted the situation as very crucial for the Greek and global economy. Some of these economists supported publicly that a new global economic recession may occur. Therefore, beyond the life-threatening issues, it was clearly communicated by the mass media in Greece that the COVID-19 pandemic may result in a huge financial crisis after the Greek dept crisis from 2009 to 2018.

The authors of this article strongly hypothesized that the life-threatening disease and the measures that the Greek government established and were enforced between March $23^{\text {rd }}$ and May $4^{\text {th }}$ of 2020 , worked for the Greek people as a common stressor from their environment. It is quite likely that the common condition of health and economic uncertainty increased the stress response of the Greeks, as well as retained their sympathetic adaptation for an exceeded time period. 


\subsection{BACKGROUND REVIEW}

According to the existing literature, the sympathetic adaptation may lead to the 'somatization' of stress through time. ${ }^{[4]}$ It is currently considered that emotions and stress interact, based on the cognitive model of 'Stress-Transactional-Theory' (STT). ${ }^{[5]}$ According to STT, stress is adapted or maladapted in the body, and this process affects -in parallel with the core 'Psychoneuroendcrinological' (PNE) response- human emotions and memory. ${ }^{[6-9]}$ Moreover, stress may last from few minutes up to several days after exposure to the stressful stimulus. In psychosomatics, both 'Acute Stress Disorder' (ASD) and 'PostTraumatic Stress Disorder' (PTSD) multimorbid with cardiovascular disease, maladaptive appraisals, also affect mood disorders, sleep disorders, somatic disorders, and many other. ${ }^{[10,11]}$

Indeed, a German study with a large effect showed that anxiety, depression and somatic diseases co-morbid $(\mathrm{N}=83,737),{ }^{[12]}$ while a Turkish study presents that the domestic COVID-19 spread affected negatively the psychosomatic health of the general population $(\mathrm{N}=533) .{ }^{[13]}$ What is more, there is a plethora of recent studies that suggest different levels of stress, stressrelated conditions and hormones based on gender ${ }^{[14-18]}$ and age. ${ }^{[19-21]}$

Regardless of the harmful interplay of stress in psychosomatic health, there are some positive health capacities such as resilience, that work as protective factors. Previous studies [22-25] show that 'Psychological Resilience' (PR) is a positive mental response to daily life stress. ${ }^{[26]}$ More precisely, PR may prevent stress escalating to distress in an unfriendly environment ${ }^{\text {[27] }}$ and act as a barrier against the negative impact of stress on mental ${ }^{[28]}$ and overall health, ${ }^{[29]}$ promoting better adaptation to it. In the case of COVID-19, a study in China shows that, indeed, the level of resilience of a medical team was higher from the according level of the community population. ${ }^{[30]}$ As a result, it was communicated that hospital staff may have to increase this capacity to find themselves in a better position on sustaining their psychosomatic health. ${ }^{[30]}$

Beyond PR, a person's ability to deal with daily stressors may be also correlated with his/her levels of 'Satisfaction with Life' (SwL). SwL probably stands in the common ground between wellbeing and wellness. To elaborate, SwL is a cognitive process widely considered as a self-reflective onein which the individuals judge their decision making in their life, having as a point of reference the place that they stand at that particular juncture. ${ }^{[31]}$ SwL, 'quality of life' and 'health-related quality of life' have been strongly correlated in past research. ${ }^{[32]}$ During the spread of COVID-19 pandemic, SwL was found in an Italian correlational study of 1,102 citizens to be correlated with perceived stress and neurotic defenses. ${ }^{[33]}$

\subsection{Aim \& Hypothesis}

On the whole, the biopsychosocial model supports that there is an interplay between biological, psychological and socio-cultural elements in mental and physical health. ${ }^{[34]}$ Taking all into account, if stress is the key element to affect psychosomatic disorders, then it is likely that psychosomatic symptoms may be affected significantly by ASD, PR, SwL, 'Days After Exposure to Stressful Stimulus' (DAESS), age and gender. Thus, the authors will test if the level of psychosomatic symptoms in the Greek population during government's precaution measures against the spread of the disease in the country between March $23^{\text {rd }}$ and May $4^{\text {th }}$ of 2020 can be predicted by six biopsychological criteria that are as follows: (i) PR, (ii) ASD, (iii) SwL, (iv) DAESS, (v) age and (vi) gender. The study is expected to contribute to the current knowledge that was provided by similar studies in Europe and East Asia regarding the impact of COVID-19 to the Greek society. 
Georgios Pilafas et.al. Predictors of psychosomatic health during the first COVID-19 outbreak in Greece. A multiple linear regression analysis in an epidemiological sample of 1,156 individuals.

\section{METHODS}

\subsection{Participants}

For the present study, a convenient sampling method ${ }^{[35]}$ was used to recruit the participants through the snowballing techniques. ${ }^{[36]}$ The recruitment process resulted in the participation of 1,158 Greek adults.

The eligibility criteria for participation were set as follows. All participants (i) had to understand the Greek language in order to read the instructions and answer the questions, (ii) had to be adults ( $\geq 18$ years old) at the time they provided their answers, (iii) had to be electronic literate, (iv) had to have access to a computer or any other electronic device that supports the use of Google Forms and (v) to use social media networks and applications such as 'Viber', 'Messenger' and 'WhatsApp' where the study was posted and communicated from one participant to the other in the 'snowballing' process. All of the participants in this study met these criteria of inclusion, and none of them was included otherwise or was provided any further assistance from the rest (e.g. hard copies of questionnaires). It is noteworthy that there were no restrictions regarding any mental and physical illnesses in the inclusion/exclusion process. These criteria were set in order to collect data from adults of every age experiencing the COVID-19 lockdown in Greece.

\begin{tabular}{|c|c|c|c|c|c|}
\hline Main Variable & $\begin{array}{c}\text { Table 1. Demogra } \\
\text { Variable's Subcategories }\end{array}$ & $\begin{array}{l}\text { Total }(\%) \\
N=1,158^{\mathrm{a}} \\
\end{array}$ & $\begin{array}{l}\text { Males (\%) } \\
\mathrm{n}=\mathbf{2 8 0},(24.2 \%)\end{array}$ & $\begin{array}{l}\text { Females }(\%) \\
\mathrm{n}=876,(75.6 \%)\end{array}$ & Missing \\
\hline \multirow[t]{4}{*}{ Education } & & & & & - \\
\hline & School Level, (\%) & $399,(34.5 \%)$ & $110,(39.3 \%)$ & $289,(33 \%)$ & \\
\hline & Undergraduate Degree, $(\%)$ & $402,(34.7 \%)$ & $85,(30.35 \%)$ & $316,(36.1 \%)$ & \\
\hline & Postgraduate Degree, $(\%)$ & $357,(30.9 \%)$ & $85,(30.35 \%)$ & $271,(30.9 \%)$ & \\
\hline \multirow[t]{8}{*}{ Marital Status } & & & & & - \\
\hline & Single, $(\%)$ & $299,(25.8 \%)$ & $111,(39.6 \%)$ & $188,(21.5 \%)$ & \\
\hline & In relationship, $<5$ years, $(\%)$ & $123,(10.6 \%)$ & $21,(7.5 \%)$ & $101,(11.5 \%)$ & \\
\hline & In relationship, $>5$ years, $(\%)$ & $74,(6.4 \%)$ & $17,(6.1 \%)$ & $56,(6.4 \%)$ & \\
\hline & Married, $(\%)$ & $508,(43.9 \%)$ & $101,(36.1 \%)$ & $407,(46.5 \%)$ & \\
\hline & Separated, $(\%)$ & $25,(2.2 \%)$ & $2,(0.7 \%)$ & $23,(2.6 \%)$ & \\
\hline & Divorced, (\%) & $113,(9.8 \%)$ & $27,(9.6 \%)$ & $86,(9.8 \%)$ & \\
\hline & Widowed, (\%) & $16,(1.4 \%)$ & $1,(0.4 \%)$ & $15,(1.7 \%)$ & \\
\hline \multirow[t]{6}{*}{ Children } & & & & & - \\
\hline & None, $(\%)$ & $527,(45.5 \%)$ & $157,(56.1 \%)$ & $368,(42 \%)$ & \\
\hline & $1,(\%)$ & $201,(17.4 \%)$ & $44,(15.7 \%)$ & $157,(17.9 \%)$ & \\
\hline & $2,(\%)$ & $348,(30.1 \%)$ & $67,(23.9 \%)$ & $281,(32.1 \%)$ & \\
\hline & $3,(\%)$ & $69,(6 \%)$ & $9,(3.2 \%)$ & $60,(6.8 \%)$ & \\
\hline & $\geq 4,(\%)$ & $13,(1.1 \%)$ & $3,(1.1 \%)$ & $10,(1.1 \%)$ & \\
\hline \multirow[t]{11}{*}{ Occupation } & & & & & - \\
\hline & Unemployed, (\%) & $84(7.3 \%)$ & $13,(4.6 \%)$ & $71,(8.1 \%)$ & \\
\hline & School \& University Student, (\%) & $163(14.1 \%)$ & $48,(17.6 \%)$ & $114,(13 \%)$ & \\
\hline & Self-Employed/Freelancer, (\%) & $142(12.3 \%)$ & $35(12.5 \%)$ & $107,(12.2 \%)$ & \\
\hline & Public Servant, $(\%)$ & $214(18.5 \%)$ & $57,(20.4 \%)$ & $157,(17.9 \%)$ & \\
\hline & Employee at the private sector, $(\%)$ & $315(27.2 \%)$ & $73,(26.1 \%)$ & $242,(27.6 \%)$ & \\
\hline & Health Professional, (\%) & $133(11.5 \%)$ & $29,(10.4 \%)$ & $103,(11.8 \%)$ & \\
\hline & Security \& Armed Forces, (\%) & $9(0.8 \%)$ & $5,(1.8 \%)$ & $4,(0.5 \%)$ & \\
\hline & Rentier/Landlord, (\%) & $13(1.1 \%)$ & $1,(0.4 \%)$ & $12,(1.4 \%)$ & \\
\hline & Retired, $(\%)$ & $76(6.6 \%)$ & $16,(5.7 \%)$ & $60,(6.8 \%)$ & \\
\hline & Disability Pension, (\%) & $9(0.8 \%)$ & $3,(1.1 \%)$ & $6,(0.7 \%)$ & \\
\hline \multirow[t]{5}{*}{ Income $^{b}$} & & & & & $1^{\mathrm{c}}$ \\
\hline & $\leq 10,000 €,(\%)$ & $379,(32.8 \%)$ & $67,(24 \%)$ & $310,(35.4 \%)$ & \\
\hline & $10,001-20,000 €,(\%)$ & $401,(34.7 \%)$ & $118,(42.1 \%)$ & $283,(32.3 \%)$ & \\
\hline & $20,001-30,000 €,(\%)$ & $174,(15 \%)$ & $44,(15.7 \%)$ & $130,(14.8 \%)$ & \\
\hline & $\geq 30,001 €,(\%)$ & $203,(17.5 \%)$ & $50,(17.9 \%)$ & $153,(17.5 \%)$ & - \\
\hline \multirow[t]{6}{*}{ Residence } & & & & & - \\
\hline & Athens, $(\%)$ & $934,(80.7 \%)$ & $237,(84.6 \%)$ & $695,(79.3 \%)$ & \\
\hline & Thessaloniki, (\%) & $24,(2.1 \%)$ & $3,(1.1 \%)$ & $21,(2.4 \%)$ & \\
\hline & Rest Mainland Greece, $(\%)$ & $118,(10.2 \%)$ & $27,(9.6 \%)$ & $91,(10.4 \%)$ & \\
\hline & Greek Islands, (\%) & $66,(5.7 \%)$ & $11,(3.9 \%)$ & $55,(6.3 \%)$ & \\
\hline & Other, non specified, (\%) & $16,(1.4 \%)$ & $2,(0.8 \%)$ & $14,(1.6 \%)$ & \\
\hline \multicolumn{6}{|c|}{$\begin{array}{l}\text { Notes: }{ }^{\text {a }} \text { Out of the } 1,158 \text { participants } 2 \text { of them }(0.2 \%) \text { did not declare their gender } \\
\text { b This variable shows the amount of the total annual income in the household after the contribution of all members } \\
\text { c The single missing case was located in the men's group }\end{array}$} \\
\hline
\end{tabular}


With regard to the demographical characteristics of the final sample, detailed information is given in Table 1 .

\subsection{COVID-19 Conditions}

As far as the conditions of the present study are concerned, all answers on electronic forms were provided only between March $23^{\text {rd }}$ and May $4^{\text {th }}$ of 2020. As already presented in the introduction, during the later time period the enforcement of obligatory precaution measures against the spread of the disease by the Greek government was taking place equally across all regions of the country.

\subsection{Sample Size}

As far as the sample size is concerned, an a priori power calculation was performed by the use of ' $\mathrm{G}^{*}$ Power 3.1'software. ${ }^{[37]}$ The amount of 1,158 provides to the study an odds ratio of 1.274 , a critical $z$ of 1.6448 and an actual power of $95 \%$.

\subsection{Materials}

\subsubsection{Psychosomatic Symptoms}

Psychosomatic symptoms were measured with the 'Psychosomatic Screening Scale -29' (PSSQ-29). ${ }^{[3]}$ The design of the scale is based on the theory of psychosomatics and the biology of the stress response. PSSQ-29 consists of 29 selfreported questions, related to stress, cognitive, affect and somatic disorders. The psychometric tool was designed for this research protocol. Pilafas et al. ${ }^{[3]}$ report that PSSQ-29 provides a high level of reliability and validity in the Greek population $(\mathrm{N}=$ $1,158)$, as Cronbach's alpha $=.955$, with one component.

\subsubsection{Psychological Resilience}

PR was measured using the translated and adapted in the Greek population version of 'Nicholson McBride Resilience Questionnaire' (NMRQ). ${ }^{[38]}$ NMRQ measures PR through 12 selfreported items. In the introductory study, the adapted version shows a notable level of validity and reliability, with $\alpha=.800(\mathrm{~N}=$ $1,158) .{ }^{[38]}$

\subsubsection{Sympathetic Nervous Adaptation}

Symptoms of sympathetic nervous adaptation were delineated by the background psychophysiological theory of the ASD. The condition was measured with the adapted and translated version of 'Acute Stress Disorder Scale' (ASDS). ${ }^{[39]}$ ASDS is a self-reported scale and includes 19 related questions. The study for the adaptation of ASDS in the Greek population shows a Cronbach's alpha score of $.925 \quad(\mathrm{~N}=$ 1,158). ${ }^{[39]}$

\subsubsection{Satisfaction with Life}

SwL was measured with the Greekadapted sort version of 'Satisfaction with Life Scale' (SWLS). ${ }^{[40]}$ The questionnaire consists of 5 self-reported items, while the reliability of the scale is found at $\alpha=.831$ in the Greek population. ${ }^{[40]}$

\subsection{Aim \& Design}

As it is already known, the design of the present study aims to identify the amount of prediction of six biopsychosocial criteria that include (i) PR, (ii) ASD, (iii) SwL, (iv) DAESS, (v) age, and (vi) gender to the overall scores of PSSQ-29.

To do so, a multiple linear regression analysis was chosen. The proposed analysis provides findings regarding the amount of prediction that the six biopsychosocial predictors provide to the variance of the level of psychosomatic symptoms, as well as their significance and weighting to the model. ${ }^{[41]}$ What is more, it was considered in advance that the six criteria are not strongly correlated to each other. This is one of the assumptions of multiple linear regression analysis. ${ }^{[41]}$ The multiple regression analysis was also chosen due to the consideration that it provides an answer regarding the question of 'contribution' of the respective predictors to the overall prediction model. ${ }^{[41]}$ 


\subsection{Procedure \& Statistical Analysis}

As long as the study received the ethical approval, the researchers selected the most relevant, valid and reliable questionnaires that were to be used, they designed the format of the study, and retrospectively uploaded it online. The data collection was performed using exclusively the 'Google Forms' electronic function between March $23^{\text {rd }}$ and May $4^{\text {th }}$ of 2020, and the study was shared through the social media networks, including also emails and applications such as 'Viber', 'Messenger' and 'WhatsApp'.

The first page to appear was the information sheet that included all the information regarding the aim and rationale of the study as well as participants' rights. The consent form followed, which demanded a personal digit code and the option of the participant's personal e-mail for the sharing of the results after the end of the research project. First survey to appear, was the demographics questionnaire followed by ASDS, NMRQ, SWLS and last PSSQ-29. At the end of the survey the participants had the option to submit their answers and were informed for their right to withdraw their participation within a week of the submission.

Data were downloaded on a excel file and coded to be transferred to SPSS version 26. ${ }^{[42]}$ Further statistical analysis took place for the present article by the use of the later electronic program. Throughout the analysis, it was found that two participants refused to declare their gender. Since the researchers had decided to use a multiple-linear analysis, those two participants were excluded from the final sample. Hence, the final number of participants was dropped into 1,156 individuals. Finally, the present article was conducted and submitted.

\section{RESULTS}

The multiple linear regression analysis took place after using the six biopsychosocial elements [ASD, PR, SwL, age, gender and DAESS] as predictors of psychosomatic symptoms. Table 2 shows the respective variables, their type of coding and the descriptive statistics observed in this study.

\begin{tabular}{|c|c|c|c|c|c|c|c|}
\hline \multirow{2}{*}{$\begin{array}{l}\text { Variable (Scale) } \\
\text { Psychosomatic Symptoms } \\
\text { (PSSQ-29) }\end{array}$} & \multicolumn{2}{|c|}{ Type of Variable } & \multirow{2}{*}{$\begin{array}{l}\text { Mean } \\
\text { Score }(\mathbf{M})\end{array}$} & \multirow{2}{*}{$\begin{array}{l}\begin{array}{l}\text { Standard } \\
\text { Deviation } \\
\text { (SD) }\end{array} \\
\pm 54.24\end{array}$} & \multirow{2}{*}{$\begin{array}{l}\begin{array}{l}\text { Range, } \\
\text { [min.-max.] }\end{array} \\
274,[0-274]\end{array}$} & \multirow{2}{*}{$\begin{array}{l}\text { Std. Error } \\
\text { (SE) } \\
1.59\end{array}$} & \multirow{2}{*}{$\begin{array}{l}\text { Missing } \\
-\end{array}$} \\
\hline & Continuous & Criterion & & & & & \\
\hline Age $^{\mathrm{a}}$ & Continuous & Predictor & 40.51 & \pm 12.84 & $60,[18-78]$ & 0.38 & - \\
\hline ASD (ASDS) & Continuous & Predictor & 38.68 & \pm 15.51 & $71,[19-90]$ & 0.46 & - \\
\hline PR (NMRQ) & Continuous & Predictor & 41.83 & \pm 7.64 & $42,[18-60]$ & 0.22 & - \\
\hline DAESS $^{\text {a }}$ & Continuous & Predictor & 33.3 & \pm 7.23 & $89,[1-90]$ & 0.21 & - \\
\hline SwL (SWLS) & Continuous & Predictor & 23.3 & \pm 6.32 & $30,[5-35]$ & 0.19 & - \\
\hline Gender $^{\mathrm{b}}$ & Nominal & Predictor & 0.76 & \pm 0.43 & $1,[0-1]$ & 0.13 & 2 \\
\hline \multicolumn{8}{|c|}{$\begin{array}{l}\text { Notes: } \\
\mathrm{N}=\text { total amount of participants } \\
\text { ' Regarding Age and DAESS a number was provided by the participants in order to convert the question into a scale variable. } \\
\text { ' Gender was declared by selecting 'male' and 'female', and it was coded as ' } 0=\text { males' and ' } 1=\text { females'. The two participants who did not } \\
\text { provided answers were excluded from the regression analysis, hence why the number of participants in the regression analysis is found at } \\
1,156 \text {. }\end{array}$} \\
\hline
\end{tabular}

\begin{tabular}{|c|c|c|c|c|c|c|c|}
\hline Variable & 1 & 2 & 3 & 4 & 5 & 6 & 7 \\
\hline 1. PSSQ-29 & - & & & & & & \\
\hline 2. Gender & $.148 * * *$ & - & & & & & \\
\hline 3. Age & $-.128 * * *$ & .034 & - & & & & \\
\hline 4. NMRQ & $-.501 * * *$ & $-.053 *$ & $.207 * * * *$ & - & & & \\
\hline 5. SWLS & $-.334 * * *$ & $.061^{*}$ & $.054 *$ & $.315^{* * * *}$ & - & & \\
\hline 6. ASDS & $.768 * * *$ & $.163 * * *$ & $-.188 * * *$ & $-.420 * * *$ & $-.311 * * *$ & - & \\
\hline 7. DAESS & -.058* & $\begin{array}{l}-.005 \\
\end{array}$ & $\begin{array}{l}.021 \\
\end{array}$ & $\begin{array}{l}.003 \\
\end{array}$ & .007 & $-.053 *$ & - \\
\hline $\begin{array}{l}\text { Notes: } \\
* \mathrm{p} \leq .05 \\
* * \mathrm{p} \leq .01 \\
* * * \mathrm{p} \leq .001\end{array}$ & & & & & & & \\
\hline
\end{tabular}


To proceed, correlation analysis was performed by the use of Pearson's r. The results show that the six biopsychosocial predictors are indeed correlated with the level of psychosomatic symptoms. Furthermore, as it was initially hypothesized in the design of the study the predictors are not all correlated to each other. This is consistent to one of the assumptions of linear-multiple regression. ${ }^{[41]}$ Pearson's $r$ correlation results are given in Table 3.

The ANOVA analysis shows that the prediction variables indeed predict the criterion, $F(6,1149)=333.892, p<.001$, Adjusted $\mathrm{R}^{2}=.634$. What is more, the regression analysis presents that the independent variables predict $63.4 \%$ of the variance in the levels of psychosomatic symptoms in this study. The later amount of prediction is considered very large in effect, since the desired result in psychology starts from $20-26 \%$ of prediction. ${ }^{[43]}$ On the contrary, a level of above $70 \%$-and until $100 \%$ - suggests that the predictors and the criterion may measure the same condition. In this study, the correlation analysis shows that none of the predictors exceeded the amount of $r>900$. ASDS presents the highest values in the relevant analysis $[\mathrm{r}=$ $.768, \mathrm{p}<.001]$. Consequently, regardless of the high prediction value, the criterion and the predictors measure different conditions.

The Durbin-Watson statistic test for autocorrelation is found at 1.96 . This result may suggest that there is barely a positive autocorrelation in the present sample. ${ }^{[43]}$ Furthermore, scores that range between 1.5 and 2.5 may suggest that the statistic values are relatively normal. ${ }^{[44]}$ What is more, values below and up to 2 in this test, may indicate that the observed values may be correlated with future values, and thus the values of this study are likely to have an impact and provide a meaning to similar future research designs. ${ }^{[45]}$

Moreover, further statistical analysis shows that out of the six biopsychosocial predictors, only four are significant to the prediction model and therefore they cannot be deleted. The non-significant predictors are (i) the gender and (ii) DAESS. In contrast, the significant ones are (i) ASD $(\beta$ $=.661, \mathrm{p}<.001)$, (ii) $\mathrm{PR}(\beta=-.209, \mathrm{p}<$ $.001)$, (iii) SwL $(\beta=.066, \mathrm{p}=.001)$ and (iv) the age of the participants $(\beta=.041, \mathrm{p}=.02)$. Table 4 summarizes the coefficients.

\begin{tabular}{|c|c|c|c|c|c|}
\hline & Unstan & zed Coefficients & Standardized Coefficients & & \\
\hline (Constant) & 51.551 & 9.808 & & 5.256 & $<001$ \\
\hline Age & .175 & .078 & .041 & 2.245 & .025 \\
\hline NMRQ & -1.483 & .144 & -.209 & -10.274 & $<.001$ \\
\hline SWLS & -.567 & .166 & -.066 & -3.411 & .001 \\
\hline DAESS & -.166 & .134 & -.022 & -1.240 & .215 \\
\hline $\begin{array}{l}\text { Notes: } \\
\mathrm{N}=1,156 \\
\text { Criterion va } \\
\text { Adjusted R } \\
\text { Significant }\end{array}$ & $\begin{array}{l}\text { Nas PSS } \\
\text { nd at .63 } \\
\text { ors to the }\end{array}$ & 1 have been boldec & & & \\
\hline
\end{tabular}

Finally, it has to be clear that the last four significant predictors [ASD, PR, SwL and age] are partial coefficients with a stronger relationship between each significant predictor and the criterion. Therefore, these four predictors control the presence of the two non-significant predictors [gender and DAESS] into the significant overall predictive model. ${ }^{[41]}$

\section{DISCUSSION}

\subsection{Summary of Findings}

To summarize the findings of the present study, the first outcome to be discussed is that most of the six biopsychosocial variables that were used in the current analysis were found to be strongly correlated with the level of psychosomatic health of the population. More specifically, gender, age, PR, SwL, 
ASD were found to be strongly correlated. What is more, the gender of the participants and the level of acute stress were both found to be positively correlated with the psychosomatic symptoms. Based on the coding of the gender variable, it seems that the outcome of the correlation analysis is more related to 'being a female participant'. The high positive correlation of psychosomatic symptoms with acute stress on the other hand, may imply that indeed the psychosomatic psychometric scale that was used in this study [PSSQ-29] is based on the psychophysiology of stress. The rest four variables that include age, resilience, SwL and DAESS were found to be strongly and positively correlated with psychosomatic health. To depict the outcome, the younger the participants were in this study, the higher they scored in psychosomatic symptom scale. This outcome also follows with PR and SwL. Practically, the correlation analysis shows that the higher the scores of psychosomatic symptoms the lower the levels of PR and SwL are observed in this study. Similarly, DAESS was negatively correlated with psychosomatic symptoms, though the level of the correlation between the two outcomes was less powerful in comparison with the rest variables. The observation may suggest the more time the participants had spent into the mandatory 'quarantine', the more psychosomatic symptoms they experienced at that juncture.

The second outcome to be discussed in this section is the fact that the predictive model shows a large effect size. This outcome may suggest that the six biopsychosocial variables that were used as predictors can predict a high ratio of variance of psychosomatic health. In a deeper look, the highest loading was found in the variable of acute stress. In this study, the later central nervous adaption was found by far the most significant predictor to the model, followed by PR. This finding supports the idea that psychosomatic health is related to the central system nervous adaption, while PR may serve as a protective capacity against the sympathetic nervous adaption. To continue, age and SwL were both found to be significant predictors in the model. However, their contribution was much limited in comparison with ASD and PR. The findings show that both age and SwL had a low weighting in the predictive model. On the contrary, the results show that DAESS and gender were not significant predictors in the model that was proposed for this research, regardless of being correlated with psychosomatic health.

\subsection{Comparing the Findings with Previous Studies}

Proceeding with the rest of the discussion, the findings of the present study are both contradictory and consistent to related study from around the world during the first spread of the COVID-19 pandemic.

To begin with, the role of the stress response was quite evident already before the COVID-19 era. For instance, Nakao and Takeuchi $(\mathrm{N}=604)^{[46]}$ tested recently what is the link of psychosocial stress and somatic disorders in psychosomatic patients at a university hospital in Tokyo, Japan. The results show that there is an association between psychosocial stress and the reported somatic symptoms. The later symptoms included mostly 'fatigue' (75.3\%), 'insomnia' (56.1\%), 'low-back pain' (49.5\%), 'headache' $(44.7 \%)$, and 'palpitations' $(43.1 \%)$. All of the aforementioned symptoms are included in the items of PSSQ-29 that was used in this study to measure the level of the experienced psychosomatic symptoms. ${ }^{[3]}$ Furthermore, the role of stress in psychosomatic medicine is again quite evident in coronavirus-related studies in Asia, Latin America and Europe. For instance, a Chinese study $(\mathrm{N}=2,182)^{[47]}$ found that sympathetic nervous adaptation is strongly related to somatic symptoms, while in India it was reported that chronic stress and anxiety were found related to somatic symptoms for a population of university students $(\mathrm{N}=329) .{ }^{[48]}$ The same result was also obtained in Colombia for a 
sample that consisted of general medical practitioners $(\mathrm{N}=539) .{ }^{[49]}$ Another similar study that recruited 332 front-line Chinese health professionals found that ASD and somatic symptoms are highly correlated. ${ }^{[50]}$ Regarding the general population, a Chinese study of 1,172 responders shows that sympathetic adaptation symptoms and psychosomatic health co-morbid while the adaption predicted the level of psychosomatics for the statistically more anxious population of that study. ${ }^{[51]}$ Again, in China, a study reported that somatic disorders and concerns about the COVID-19 were correlated in a sample of 399 college and primary school students. ${ }^{[52]}$ These findings are also obtained in European populations, where -for instance- 103 Italian health professionals experienced both psychological and physical distress. ${ }^{[53]}$ Another European study that consists of 170 Polish citizens reported that the nervous adaptation is indeed strongly correlated with psychosomatic disorders. ${ }^{[54]}$ In the UK, Shelvin et al. $(\mathrm{N}=2,025)^{[55]}$ found that psychosomatic health and sympathetic adaptation are associated. It is noteworthy that most research investigated the somatization of the COVID-19 pressure using various psychometric tools of central nervous adaption that measured the psychological symptoms within the time frame of 2 weeks. In this study the mean number of days that had passed from the domestic lockdown were 33 . Therefore, the mean days stand between the deferential criterion between ASD and PTSD. ${ }^{[56,57]}$ Various studies also highlight that stressrelated symptoms that may be included in the diagnostic criteria for PTSD are strongly related to somatic symptoms in the COVID19 era. $^{[58-60]}$

On the other hand, the second most significant predictor in the model of this study was found to be the level of PR, which worked as a protective factor for psychosomatic health. In Greece, little evidence supported the link between psychosomatic health and resilience before the COVID-19 outbreak. To depict,
Karampas et al. ${ }^{[61]}$ found that resilience is correlated with positive emotions and better psychosomatic health in 395 Cadets of the Hellenic Army NCO Academy. The levels of psychosomatic health were measured in three subcategories that are again included in PSSQ-29. These are the (i) somatic symptoms, (ii) anxiety levels and insomnia, (iii) social dysfunction and (iv) severe depression. The results of Karampas et al. ${ }^{[61]}$ may be consistent to the findings of this study. With regard to the COVID-19 findings around the world, a Chinese correlational study $(\mathrm{N}=160)^{[30]}$, which took place during the domestic spread of COVID-19, found that medical personal with higher levels of mental resilience experienced less influence in their psychosomatic state. In addition, personal resilience was found to be significant against negative nervous adaption symptoms in the Philippines. ${ }^{[62]}$ Resilience was also found a protective capacity in another Chinese study in which the authors recruited 1,770 participants from the general population. ${ }^{[63]}$ Unfortunately, beyond the two later Chinese studies, psychological resilience was not investigated in any other studies during any domestic COVID-19 at any country. What is more, there is a clear absence of European studies that investigate any protective role in psychosomatic health, although the capacity is in theory a positive component against the development of sympathetic adaption. ${ }^{[38]}$

Proceeding with the rest of the findings, recent COVID-19 studies show clearly the protective role of SwL. Similarly, to this study, SwL was found to be protective against the sympathetic adaptation response of 325 front-line nurses in Philippines during the spread of the pandemic. $^{[62]}$ In Poland, an empirical research found that 914 students at a single university experience lower levels of general health and satisfaction with life. ${ }^{[64]}$ The sample also experienced higher levels of sympathetic adaptation. The authors discussed that the level of anxiety that was measured in a self-reported questionnaire 
that asks about psychological symptoms of sympathetic nervous adaption over the course of the last two weeks was predicted partly by SwL. ${ }^{[64]}$

Additionally, the findings of the present study with regard to age are consistent to previous related study from other countries. To support the later statement, 'being over 50 years old' was found amongst other predictors to be a significant variable for a prediction model of psychophysiological symptoms in a Chinese epidemiological study during the COVID-19 spread $(\mathrm{N}=1,060) .{ }^{[65]}$ Another epidemiological study in Italy reported that gender was again, a significant predictor for mental and somatic conditioning during the spread of the pandemic in the country $(\mathrm{N}=$ 6,412). ${ }^{[66]}$ Furthermore, participants aged 'below 35 years old' were found more prone in experiencing more stress in Austria $(\mathrm{N}=$ $1,005)^{[67]}$ and the UK $(\mathrm{N}=1,006) .{ }^{[68]}$

Controversially, the finding that did not follow the outcomes of other related COVID-19 studies is the one of gender. To be specific, although in the present study gender was found a non-significant predictor in the model, there is a plethora of studies that found the opposite result. To illustrate, an epidemiological study in China found that 'being a woman' predicted somatic disorders, while 'being a man' was associated with the level of sympathetic symptoms that works as a risk factor for psychosomatic health $(\mathrm{N}=1,134) .{ }^{[69]}$ Similarly, 'being a female' was also found to be associated with psychophysical health in epidemiological studies in Italy $(\mathrm{N}=$ $6,412),{ }^{[66]}$ Austria $(\mathrm{N}=1,005)^{[67]}$ and the UK $(\mathrm{N}=1,006) .{ }^{[68]}$ The only study that may partly support the findings of this research, is an epidemiological study from China $(\mathrm{N}=$ 1,060). ${ }^{[65]}$ The authors discussed that there are no significant differences in the levels of psychophysiological symptoms between the two genders.

Last but not least, DAESS was not found significant in the predictive model. The basic theory of psychosomatic medicine discusses about the progress of somatic disorders, which evolve through time in parallel with mental disorders. ${ }^{[46]}$ Hence, it was strongly hypothesized by the authors of this study that participants who had been in a quarantine for a longer time period, would show higher level of psychosomatic symptoms. Unfortunately, there is a clear absence of empirical research about the role of time in the progress of psychosomatic symptoms when people are in a domestic COVID-19 quarantine, and thus no comparisons may be observed upon this particular finding of the present research.

Finally, as far as the two main predictors that show the highest contribution to the predictive model are concerned, ASD was found to be predominantly the most significant criterion with the highest contribution to the model. This is a highly anticipated result, since already the rationale of psychosomatics -probably from the era of Walter Cannon in the fight-or-flight response ${ }^{[70]}$ - require the activation the PNE response of the Hypothalamic-PituitaryAdrenal (HPA) Axis as it was described in the original theory of the 'general adaptation syndrome' by Hans Selye. ${ }^{[71]}$ Again, it was not surprising that PR was the second most important predictor in this study. PR, in essence, is a response to stress and is delineated as a tool against distress. ${ }^{[72-74]}$ Another consideration regarding PR is that it may turn a 'negative' stimulus to a 'neutral' if not to a 'positive' one. To be specific, PR may contribute firstly to experience 'eustress' instead of 'distress', under the same stressful event, ${ }^{[75]}$ and secondly to increase Aaron Antonovsky's 'salutogenenic model' and the 'sense of coherence'. ${ }^{[76]}$

\subsection{Limitations}

With regard to the limitations of this particular study, two main issues should be raised. Firstly, in this study a convenient sample was used. The participants were all electronically literate and they had to have access to electronic devices that could support the use of Google Forms, emails, social media and applications such as 
'Viber', 'Messenger' and 'WhatsApp'. Thus, it is quite likely that only Greeks who had access to these electronic functions had the chance to submit any answers. The snowball recruiting strategy and the convenient sample that was finally used may present issues of credibility, sampling error and selection bias. Secondly, the people who participated were all Greeks. This limits the impact of the findings to a national level and cross-cultural generalization may increase the likelihood of cultural bias. What is more, the sequence between the two genders is unequal, since approximately two thirds of the participants are females. This highlights that men were less likely to participate. Further, 8 out of 10 participants declared that they live permanently in Athens, Greece, although the respective distribution of residency in reality is approximately 4 out 10 Greeks.

\subsection{Future Research}

In regard to future research, it is reflected that the findings of the present study may show some future directions. For instance, future research in psychosomatic health may include more capacities of positive health psychology in any upcoming prediction model, including self-efficacy, optimism, religiosity and spirituality. Second, throughout the literature review that was performed for this article it was almost evident that there is an absence of studies from specific geographic regions like South American, Sub-Saharan Africa and Oceania. Regardless of that, it is encouraged the use of resilience in European studies, since most evidence was retrieved from East Asian countries. Future studies that will investigate the impact of other pandemic on psychosomatic health may also include questionnaires that are specifically designed for the disease, e.g. 'coronophobia' scales. Lastly, it is highly suggested for future protocols to include questions regarding 'having regular exercise' and 'experiencing a chronic illness or condition' in the demographic questionnaire for further statistical analysis.

\section{CONCLUSIONS}

On the whole, the present study took place during the first wave of the COVID19 in Greece. Data collection was performed through an electronic survey, while the authors used the snowball strategy. It was initially hypothesized that the spread of COVID-19 and its outcomes on people's health and the local economy would have all created a stressful environment for the Greeks who would retrospectively had increased the sympathetic nervous adaptation and symptoms as described in psychosomatic medicine. Hence, the researchers of this article tested whether ASD, PR, SwL, age, gender and the DAESS would all create a significant prediction model for psychosomatic health. The findings show that indeed the model predicts the criterion with a large effect. ASD and PR were found to be the most important variables. This finding was consistent to the background literature and previous studies regarding the harmful role of stress in psychosomatic health and the protective one of psychological resilience. Little effect in the predictive model was observed regarding 'age' and SwL. This outcome also follows previous findings and the background theories in the relevant fields. On the contrary, gender and DAESS were found not significant in the predictive model. The result about gender is not consistent to previous epidemiological studies in Europe and East Asia, while research regarding DAESS was probably excluded in most previous COVID-19 studies. The study is overall confirmatory to previous research on sympathetic adaptation and psychosomatic health in epidemiological studies that investigated the impact of COVID-19 in the domestic general population, while it may have opened further research opportunities with regard to the role of capacities of positive health psychology on psychosomatic health for European populations. 


\section{ACKNOWLEDGMENTS}

All authors express their thankfulness to every participant and all of our close people for their support throughout the COVID-19 lockdown. The authors also thank Mrs. Anastasia Dermati and Mr. Dimitrios Papaioannou for their help in the data collection process, and transfer to SPSS software.

Ethical Approval: The research protocol was approved by the Ethics Committee of Research and Conduct of City Unity College and City Unity Psychology Research Center in Athens, Greece. The approval reference number is 2020PSYRSC003. The Committee follows the 1964 Declaration of Helsinki on ethical principles and the domestic law.

\section{Conflict of Interest: None}

\section{Source of Funding: None}

\section{REFERENCES}

1. Strongylaki NP, Dermati A, Pilafas G, Menti D, Lyrakos G. Effect of Coping Strategies on Acute Stress during the COVID-19 Pandemic in Greece. Health \& Research Journal; in press.

2. Parlapani E, Holeva V, Voitsidis P, Blekas A, Gliatas I, Porfyri GN, Golemis A, Papadopoulou K, Dimitriadou A, Chatzigeorgiou AF, Bairachtari V. Psychological and behavioral responses to the COVID-19 pandemic in Greece. Frontiers in Psychiatry 2020; 11:821.

3. Pilafas G, Prouzou A, Strongylaki NP, Menti D, Lyrakos G. Introducing the 'Psychosomatic Screening Questionnaire29' (PSSQ-29). Reliability and Validity in an Epidimiological Sample. International Journal of Health Sciences and Research; in press

4. Deter HC, Orth-Gomér K, Wasilewski B, Verissimo R. The European Network on Psychosomatic Medicine (ENPM)-history and future directions. BioPsychoSocial medicine 2017; 11(1):1-4.

5. Byers JF, Smyth KA. Application of a transactional model of stress and coping with critically ill patients. Dimensions of critical care nursing: DCCN 1997; 16(6):292-300.

6. Biondi M, Bersani FS, Pasquini M. The Role of Integrated Interventions in Psychosomatic Diseases. In: Grassi L, Riba, MB, Wise, T, editors. Person Centered Approach to Recovery in Medicine: Insights from Psychosomatic Medicine and Consultation-Liaison Psychiatry. Springer International Publishing; 2019. p. 263-277.

7. Obbarius N, Fischer F, Obbarius A, Nolte $S$, Liegl G, Rose M. A 67-item stress resilience item bank showing high content validity was developed in a psychosomatic sample. Journal of clinical epidemiology 2018; 100:1-2.

8. Williams K, Lund TJ, Liang B, Mousseau $\mathrm{AD}$, Spencer R. Associations between stress, psychosomatic complaints, and parental criticism among affluent adolescent girls. Journal of Child and Family Studies 2018; 27(5):1384-93.

9. Yu NX, Chan JS, Ji X, Wan AH, Ng SM, Yuen LP, Chan CL, Chan CH. Stress and psychosomatic symptoms in Chinese adults with sleep complaints: mediation effect of self-compassion. Psychology, health \& medicine 2019; 24(2):241-52.

10. Bourn LE, Sexton MB, Raggio GA, Porter KE, Rauch SA. Posttraumatic stress disorder and somatic complaints: Contrasting Vietnam and OIF/OEF Veterans' experiences. Journal of psychosomatic research 2016; 82:35-40.

11. Gradus JL. Prevalence and prognosis of stress disorders: a review of the epidemiologic literature. Clinical epidemiology 2017; 9:251.

12. Asselmann E, Venz J, Pieper L, Wittchen HU, Pittrow D, Beesdo-Baum K. The role of gender and anxiety in the association between somatic diseases and depression: findings from three combined epidemiological studies in primary care. Epidemiology and psychiatric sciences 2019; 28(3):321.

13. Gica S, Kavakli M, Durduran Y, Ak M. The Effect of COVID-19 pandemic on psychosomatic complaints and investigation of the mediating role of intolerance to uncertainty, biological rhythm changes and perceived COVID-19 threat in this relationship: A web-based community survey. Personnel 2020; 11(14):15. 
14. Bangasser DA, Eck SR, Sanchez EO. Sex differences in stress reactivity in arousal and attention systems. Neuropsychopharmacology 2019; 44(1):129-39.

15. Boisclair Demarble J, Fortin C, D'Antono B, Guay S. Gender differences in the prediction of acute stress disorder from peritraumatic dissociation and distress among victims of violent crimes. Journal of interpersonal violence 2020; 35(5-6):122950.

16. Handa RJ, Chung WC. Chapter 14 - Gender and Stress. Stress: Physiology, Biochemistry, and Pathology. Amsterdam, Netherlands: Elsevier; 2019. p.165-76.

17. Spagnolo PA, Manson JE, Joffe H. Sex and gender differences in health: what the COVID-19 pandemic can teach us. Annals of Internal Medicine. 2020.

18. Thibaut F, Jhanwar VG. Gender differences: The new challenge for the next years. Indian journal of psychiatry 2020; 62(2):112.

19. Hodes GE, Epperson CN. Sex differences in vulnerability and resilience to stress across the life span. Biological psychiatry 2019; 86(6):421-32.

20. Martins-Klein B, Bamonti PM, Owsiany M, Naik A, Moye J. Age differences in cancerrelated stress, spontaneous emotion regulation, and emotional distress. Aging \& mental health 2021; 25(2):250-9.

21. Peltier MR, Verplaetse TL, Mineur YS, Petrakis IL, Cosgrove KP, Picciotto MR, McKee SA. Sex differences in stress-related alcohol use. Neurobiology of stress 2019; 10:100149.

22. Jung YH, Ha TM, Oh CY, Lee US, Jang JH, Kim J, Park JO, Kang DH. The effects of an online mind-body training program on stress, coping strategies, emotional intelligence, resilience and psychological state. PloS one 2016; 11(8):e0159841.

23. Magtibay DL, Chesak SS, Coughlin K, Sood A. Decreasing stress and burnout in nurses: efficacy of blended learning with stress management and resilience training program. JONA: The Journal of Nursing Administration 2017; 47(7/8):391-5.

24. Rosenberg AR, Bradford MC, Junkins CC, Taylor M, Zhou C, Sherr N, Kross E, Curtis JR, Joyce P. Effect of the promoting resilience in stress management intervention for parents of children with cancer (PRISMP): a randomized clinical trial. JAMA network open 2019; 2(9):e1911578-.
25. Rzeszutek M, Oniszczenko W, FirlągBurkacka E. Social support, stress coping strategies, resilience and posttraumatic growth in a Polish sample of HIV-infected individuals: results of a 1year longitudinal study. Journal of Behavioral Medicine 2017; 40(6):942-54.

26. Shields GS, Slavich GM. Lifetime stress exposure and health: A review of contemporary assessment methods and biological mechanisms. Social and Personality Psychology Compass 2017; 11(8):e12335.

27. Takayama N, Morikawa T, Bielinis E. Relation between psychological restorativeness and lifestyle, quality of life, resilience, and stress-coping in forest settings. International journal of environmental research and public health 2019; 16(8):1456.

28. Yu NX, Chan JS, Ji X, Wan AH, Ng SM, Yuen LP, Chan CL, Chan CH. Stress and psychosomatic symptoms in Chinese adults with sleep complaints: mediation effect of self-compassion. Psychology, health \& medicine 2019; 24(2):241-52.

29. Sinha R, Lacadie CM, Constable RT, Seo D. Dynamic neural activity during stress signals resilient coping. Proceedings of the National Academy of Sciences 2016; 113(31):8837-42.

30. xu X, Guangyao L, Shunhong H, Bin L, Sibing Z. Investigation, Analysis and Management Application of Mental Resilience and Psychosomatic State of The Medical Team Against COVID-19 [Internet]. In Review; 2020 Jun [cited 2021 May 22]. Available from: https://www.researchsquare.com/article/rs29149/v1

31. López-Ortega M, Torres-Castro S, RosasCarrasco O. Psychometric properties of the Satisfaction with Life Scale (SWLS): secondary analysis of the Mexican Health and Aging Study. Health and Quality of Life Outcomes 2016; 14(1):1-7.

32. Lorenzo-Seva U, Calderon C, Ferrando PJ, del Mar Muñoz M, Beato C, Ghanem I, Castelo B, Carmona-Bayonas A, Hernández R, Jiménez-Fonseca P. Psychometric properties and factorial analysis of invariance of the satisfaction with life scale (SWLS) in cancer patients. Quality of Life Research 2019; 28(5):1255-64. 
33. Gori A, Topino E, Di Fabio A. The protective role of life satisfaction, coping strategies and defense mechanisms on perceived stress due to COVID-19 emergency: A chained mediation model. Plos one 2020; 15(11):e0242402.

34. Engel GL. The need for a new medical model: a challenge for biomedicine. Science 1977;196(4286):129-36.

35. Palinkas LA, Horwitz SM, Green CA, Wisdom JP, Duan N, Hoagwood K. Purposeful sampling for qualitative data collection and analysis in mixed method implementation research. Administration and policy in mental health and mental health services research 2015; 42(5):533-44.

36. Goodman LA. Snowball sampling. The annals of mathematical statistics. 1961. p. $148-70$.

37. Faul F, Erdfelder E, Buchner A, Lang A-G. Statistical power analyses using $\mathrm{G}^{*}$ Power 3.1: Tests for correlation and regression analyses. Behavior Research Methods 2009; 41(4):1149-60.

38. Pilafas G, Strongylaki NP, Papaioannou D, Menti D, Lyrakos G. Adaptation of" Nicholson McBride Resilience Questionnaire"(NMRQ) in Greek. A reliability and validity study in an epidemiological Greek sample. Health \& Research Journal 2020; 6(4):123-31.

39. Pilafas G, Strongylaki NP, Menti D, Lyrakos G. Introducing the Greek adaptation of acute stress disorder scale'(ASDS). High reliabil-ity and validity in an epidemiological sample. Health \& Research Journal 2021; 7(2):65-73.

40. Lyrakos GN, Xatziagelaki E, Papazafiropoulou AK, Batistaki C, Damigos D, Mathianakis G, Bousboulas S, Spinaris V. 1439-Translation and validation study of the satisfaction with life scale (swls) in greek general population, diabetes mellitus and patients with emotional disorders. European Psychiatry 2013; 28(S1):1-.

41. Field A, Miles J, Field Z. Discovering statistics using R. Sage publications; 2012.

42. IBM Corp. IBM SPSS Statistics for Windows. Armonk, NY: IBM Corp; 2020

43. Miles J. R Squared, Adjusted R Squared. In: Wiley StatsRef: Statistics Reference Online. American Cancer Society 2014.

44. Field A. Discovering Statistics Using SPSS. $3^{\text {rd }}$ edition. SAGE Publications; 2009.
45. Chatterjee S, Simonoff JS. Handbook of regression analysis. Hoboken, NJ: Wiley; 2013.

46. Nakao M, Takeuchi T. Alexithymia and somatosensory amplification link perceived psychosocial stress and somatic symptoms in outpatients with psychosomatic illness. Journal of clinical medicine 2018; 7(5):112.

47. Zhang WR, Wang K, Yin L, Zhao WF, Xue Q, Peng M, Min BQ, Tian Q, Leng HX, Du JL, Chang H. Mental health and psychosocial problems of medical health workers during the COVID-19 epidemic in China. Psychotherapy and psychosomatics 2020; 89(4):242-50.

48. Majumdar P, Biswas A, Sahu S. COVID-19 pandemic and lockdown: cause of sleep disruption, depression, somatic pain, and increased screen exposure of office workers and students of India. Chronobiology International 2020; 37(8):1191-200.

49. Monterrosa-Castro A, Redondo-Mendoza V, Mercado-Lara M. Psychosocial factors associated with symptoms of generalized anxiety disorder in general practitioners during the COVID-19 pandemic. Journal of Investigative Medicine 2020; 68(7):122834.

50. Wang Y, Duan Z, Peng K, Li D, Ou J, Wilson A, Wang N, Si L, Chen R. Acute stress disorder among frontline health professionals during the COVID-19 outbreak: a structural equation modelling investigation. Psychosomatic Medicine 2021.

51. Huang Y, Wang Y, Zeng L, Yang J, Song X, Rao W, Li H, Ning Y, He H, Li T, Wu K. Prevalence and correlation of anxiety, insomnia and somatic symptoms in a Chinese population during the COVID-19 epidemic. Frontiers in psychiatry 2020; 11:894.

52. Liu S, Liu Y, Liu Y. Somatic symptoms and concern regarding COVID-19 among Chinese college and primary school students: A cross-sectional survey. Psychiatry research 2020; 289:113070.

53. Marinaci T, Carpinelli L, Venuleo C, Savarese G, Cavallo P. Emotional distress, psychosomatic symptoms and their relationship with institutional responses: A survey of Italian frontline medical staff during the Covid-19 pandemic. Heliyon 2020; e05766. 
54. Wielgus B, Urban W, Patriak A, Cichocki Ł. Examining the Associations between Psychological Flexibility, Mindfulness, Psychosomatic Functioning, and Anxiety during the COVID-19 Pandemic: A Path Analysis. International Journal of Environmental Research and Public Health 2020; 17(23):8764.

55. Shevlin M, Nolan E, Owczarek M, McBride O, Murphy J, Gibson Miller J, Hartman TK, Levita L, Mason L, Martinez AP, McKay R. COVID-19-related anxiety predicts somatic symptoms in the UK population. British Journal of Health Psychology 2020; 25(4):875-82.

56. American Psychiatric Association. Diagnostic and statistical manual of mental disorders (DSM-5®). American Psychiatric Pub 2013.

57. World Health Organization. ICD-10 (Version:2019). 2019

58. Hou T, Zhang R, Song X, Zhang F, Cai W, Liu Y, Dong W, Deng G. Self-efficacy and fatigue among non-frontline health care workers during COVID-19 outbreak: A moderated mediation model of posttraumatic stress disorder symptoms and negative coping. PloS one 2020; 15(12); $\mathrm{e} 0243884$.

59. Jowett S, Shevlin M, Hyland P, Karatzias T. Posttraumatic Stress Disorder and Persistent Somatic Symptoms During the COVID-19 Epidemic: The Role of Sense of Threat. Psychosomatic Medicine 2020.

60. Zhang H, Shi Y, Jing P, Zhan P, Fang Y, Wang F. Posttraumatic stress disorder symptoms in healthcare workers after the peak of the COVID-19 outbreak: A survey of a large tertiary care hospital in Wuhan. Psychiatry research 2020; 294:113541.

61. Karampas K, Michael G, Stalikas A. Positive emotions, resilience and psychosomatic heath: Focus on Hellenic army NCO cadets. Psychology 2016; 7(13):1727-40.

62. Labrague LJ, De los Santos JA. COVID-19 anxiety among front-line nurses: Predictive role of organisational support, personal resilience and social support. Journal of nursing management 2020; 28(7):1653-61.

63. Ran L, Wang W, Ai M, Kong Y, Chen J, Kuang L. Psychological resilience, depression, anxiety, and somatization symptoms in response to COVID-19: A study of the general population in China at the peak of its epidemic. Social Science \& Medicine 2020; 262:113261.

64. Rogowska AM, Kuśnierz C, Bokszczanin A. Examining anxiety, life satisfaction, general health, stress and coping styles during COVID-19 pandemic in Polish sample of university students. Psychology Research and Behavior Management 2020; 13:797.

65. Tian F, Li H, Tian S, Yang J, Shao J, Tian C. Psychological symptoms of ordinary Chinese citizens based on SCL-90 during the level I emergency response to COVID19. Psychiatry research 2020; 288:112992.

66. Conversano C, Di Giuseppe M, Miccoli M, Ciacchini R, Gemignani A, Orrù G. Mindfulness, age and gender as protective factors against psychological distress during Covid-19 pandemic. Frontiers in psychology 2020; 11:1900.

67. Pieh C, Budimir S, Probst T. The effect of age, gender, income, work, and physical activity on mental health during coronavirus disease (COVID-19) lockdown in Austria. Journal of psychosomatic research 2020; 136:110186.

68. Pieh C, Budimir S, Delgadillo J, Barkham M, Fontaine JR, Probst T. Mental health during COVID-19 lockdown in the United Kingdom. Psychosomatic medicine 2020.

69. Shangguan F, Quan X, Qian W, Zhou C, Zhang C, Zhang XY, Liu Z. Prevalence and correlates of somatization in anxious individuals in a Chinese online crisis intervention during COVID-19 epidemic. Journal of Affective Disorders 2020; 277:436-42.

70. McCarty R. The Fight-or-Flight Response: A Cornerstone of Stress Research. In: Fink G, editor. Stress: Concepts, Cognition, Emotion, and Behavior. Academic Press; 2016. p. 33-37.

71. Szabo S. The Origins \& Evolution of Stress Research: From Distress to Eustress. The FASEB Journal 2020; 34(S1):1-.

72. Li ZS, Hasson F. Resilience, stress, and psychological well-being in nursing students: A systematic review. Nurse education today $2020 ; 104440$.

73. McEwen BS. In pursuit of resilience: stress, epigenetics, and brain plasticity. Annals of the New York Academy of Sciences 2016; 1373(1):56-64.

74. Walker FR, Pfingst K, Carnevali L, Sgoifo A, Nalivaiko E. In the search for integrative 
Georgios Pilafas et.al. Predictors of psychosomatic health during the first COVID-19 outbreak in Greece. A multiple linear regression analysis in an epidemiological sample of 1,156 individuals.

biomarker of resilience to psychological stress. Neuroscience \& Biobehavioral Reviews 2017; 74:310-20.

75. Lee HJ, Shim I, Pyun KH. Resilient to Stress: Proposed a Novel Type E Personality. Korean Journal of Stress Research 2017; 25(3):209-12.

76. Mc Gee SL, Höltge J, Maercker A, Thoma MV. Sense of coherence and stress-related resilience: Investigating the mediating and moderating mechanisms in the development of resilience following stress or adversity. Frontiers in Psychiatry 2018; 9:378.

How to cite this article: Pilafas G, Prouzou A, Strongylaki NP et.al. Predictors of psychosomatic health during the first COVID19 outbreak in Greece. A multiple linear regression analysis in an epidemiological sample of 1,156 individuals. Int $J$ Health Sci Res. 2021; 11(6): 274-289. DOI: https://doi. org/10.52403/ijhsr.20210641 